\title{
Blue Rubber Bleb Nevus Syndrome: A Possible Cause for Growth Retardation and Pubertal Delay
}

\author{
Yi Pan ${ }^{\text {a }}$ Lu Zhang $^{\text {a }}$ Minghui Duan ${ }^{a}$ Hong Yang ${ }^{b}$ Duoduo Zhao ${ }^{a}$ \\ Weifeng $\mathrm{Li}^{\mathrm{a}}$ \\ aDepartment of Hematology, Peking Union Medical College Hospital, Chinese Academy of Medical Sciences and \\ Peking Union Medical College, Beijing, PR China; ${ }^{b}$ Department of Gastroenterology, Peking Union Medical College \\ Hospital, Chinese Academy of Medical Sciences and Peking Union Medical College, Beijing, PR China
}

\section{Significance of the Study}

- Blue rubber bleb nevus (BRBNS) syndrome is a rare disorder characterized by multiple venous malformations predominantly in the skin and gastrointestinal tract, seldom affecting growth and development. Here, we report a case of BRBNS with growth retardation and pubertal delay.

\section{Keywords}

Blue rubber bleb nevus syndrome · Iron deficiency anemia · Growth retardation Pubertal delay

\footnotetext{
Abstract

Objective: The aim of this paper was to describe a rare case of blue rubber bleb nevus (BRBNS) with growth retardation and pubertal delay. Clinical Presentation and Intervention: A 16-year-old boy with severe iron deficiency anemia was diagnosed with BRBNS, showing growth retardation and pubertal delay simultaneously. The patient was treated conservatively with intravenous iron therapy, and his puberty advanced gradually. Conclusion: Given that growth retardation and pubertal delay are rare in BRBNS patients, this case reminds us to include BRBNS in the differential diagnosis of growth retardation.

(c) 2019 The Author(s)

Published by S. Karger AG, Basel
}

\section{KARGER}

E-Mail karger@karger.com www.karger.com/mpp

\section{The Author(s) Published by S. Karger AG, Basel \\ Karger \\ Open access}

This is an Open Access article licensed under the Creative Commons Attribution-NonCommercial-4.0 International License (CC BY-NC) (http://www.karger.com/Services/OpenAccessLicense), applicable to the online version of the article only. Usage and distribution for commercial purposes requires written permission.

\section{Introduction}

Blue rubber bleb nevus (BRBNS) is a rare venous malformation characterized by multifocal blue-to-purple rubbery lesions. The symptoms caused by BRBNS depend on the size and location of venous malformation. Although BRBNS is a disease that could occur at an early age, concurrence of pubertal delay is extremely rare. Here, we report a case of an adolescent with BRBNS who presented with growth retardation and delayed puberty.

\section{Case Report}

A 16-year-old boy was referred to our hospital due to anemia and pubertal delay. He presented with a 7-year history of refractory iron deficiency anemia (IDA), which did not respond to oral iron supplementation. Moreover, although his length and weight

Zhang Lu, Department of Hematology

Peking Union Medical College Hospital, Chinese Academy of

Medical Sciences and Peking Union Medical College

Dongdansantiao Street, Dongcheng District, Beijing 100730 (PR China)

E-Mail pumczhanglu@126.com 

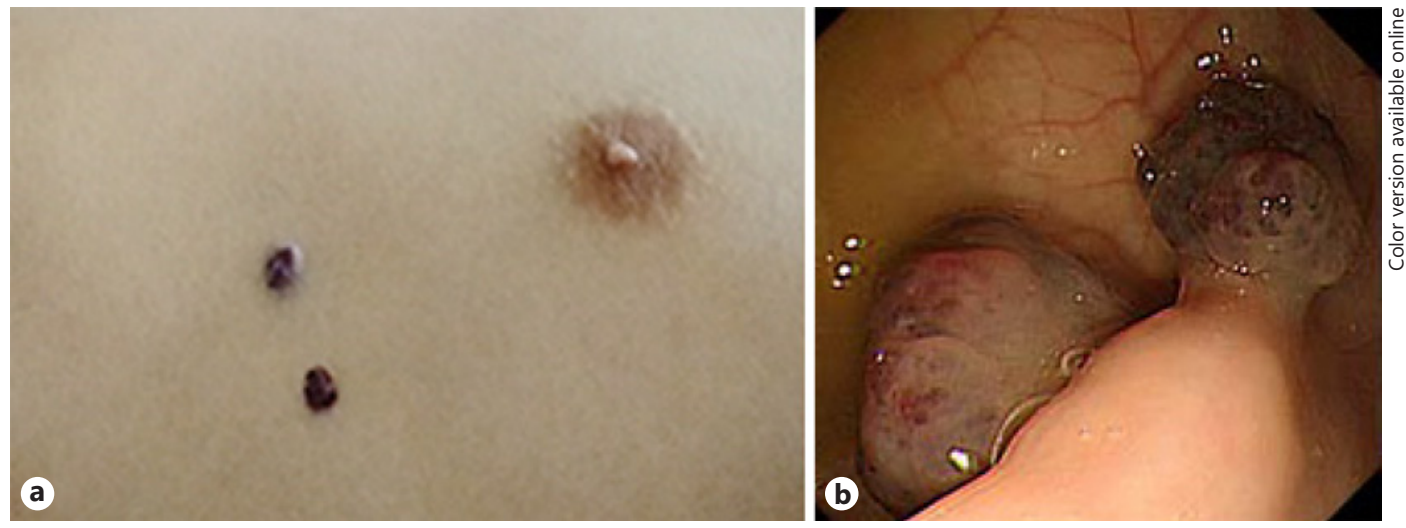

Fig. 1. Venous malformations in the patient. a Multiple dark purple rubber-like soft-tissue masses on the chest wall. b Endoscopy findings revealing numerous distinctive venous malformations in the gastrointestinal tract.

at birth were normal, he appeared with short stature and pubertal delay without secondary sexual characteristics and was diagnosed with partial deficiency of growth hormone $(\mathrm{GH})$ in another hospital 1 year ago. Besides, he had a prominent history of blue-black nodules of various sizes, which gradually appeared and enlarged on his back and extremities since the age of 3 years. He had no relevant family history of similar symptoms.

Physical examination indicated that the blue-black rubber-like soft-tissue masses ranging from $5 \mathrm{~mm}$ to $5 \mathrm{~cm}$ were on the neck, upper and lower limbs, chest walls, and back (Fig. 1a). The patient was $154 \mathrm{~cm}$ (<3rd percentile) in height and $39 \mathrm{~kg}$ ( $<3 \mathrm{rd}$ percentile) in weight. His pubic hair was Tanner 1, length of penis shorter than $2.5 \mathrm{~cm}$ and bilateral testicular volume about $5 \mathrm{~mL}$. In addition, this patient had no mental retardation.

The laboratory examinations prior to intravenous iron supplementation in reference to the normal range (NR) were listed as follows: hemoglobin, $41 \mathrm{~g} / \mathrm{L}$ (NR 120-160); mean corpuscular volume, 71.8 fL (NR 82-97); mean corpuscular hemoglobin, 17.5 pg (NR 27-32); mean corpuscular hemoglobin concentration, 244 g/L (NR 320-360); serum iron, $5.7 \mu \mathrm{g} / \mathrm{dL}$ (65-175); serum ferritin, $4 \mathrm{ng} / \mathrm{mL}$ (NR 24-336); total iron-binding capacity $437 \mu \mathrm{g} / \mathrm{dL}(250-$ 450 ); and transferrin saturation percentage 1.2\% (NR 25.0-50.0\%). White blood cell and platelet counts were normal. Bone marrow aspiration revealed normocellular marrow and depleted iron stores. Fecal occult blood test was positive. Hormonal assays showed that the levels of luteinizing hormone, follicular-stimulating hormone, and testosterone were within NRs.

Ultrasonography suggested that cystic masses with low Doppler signal were found on the chest wall, back, and buttock. Endoscopy showed multiple scattered bluish-to-purplish venous malformations throughout the entire gastrointestinal tract (Fig. 1b). Besides, computed tomography scans of the thorax, abdomen, and pelvis demonstrated that there were no similar lesions in other organs.

Based on the clinical manifestations and endoscopy findings, the patient was diagnosed as BRBNS with growth retardation and pubertal delay. After supplementation with intravenous iron for 1 month without other interventions, hemoglobin levels had in- creased to $87 \mathrm{~g} / \mathrm{L}$. As for physical changes, his height increased to $158 \mathrm{~cm}$ and his weight was $44 \mathrm{~kg}$. Additionally, his pubic hair advanced to Tanner 2 .

\section{Discussion}

This is the first report in the literature of an adolescent with BRBNS presenting with growth retardation and delayed puberty due to IDA. BRBNS is a rare sporadic disorder characterized by multiple multifocal venous malformations primarily involving the skin and gastrointestinal tract. Additionally, somatic mutations in TEK encoding TIE2 were discovered in individuals with BRBNS and determined as the cause of BRBNS [1].

Venous malformations may occur anywhere in the gastrointestinal tract, predominantly affecting the small intestines. Gastrointestinal lesions can cause hemorrhage easily, leading to chronic IDA. Besides, other organs such as the musculoskeletal system and cardiovascular system may also be involved [2].

IDA is usually asymptomatic or manifested as nonspecific symptoms including weakness and fatigue due to the low tissue delivery of oxygen and decreased activity of iron-containing enzymes. Nonhematologic effects of IDA, such as abnormal growth and mental retardation, have been reported [3]. In addition, it is known that chronic anemia can also have an impact on $\mathrm{GH}$ and insulin-like growth factor-I [4]. This patient was once diagnosed as having partial GH deficiency, and thus we speculated that growth impairment and pubertal delay may be associated with defective $\mathrm{GH}$-insulin-like growth factor-I 
secretion caused by IDA. Moreover, considering the extent of gastrointestinal involvement in this patient, malabsorption may occur, contributing to growth retardation. Although the etiology is not thoroughly elucidated, the dramatic changes in our patient indicated a possible causal relationship between IDA and pubertal delay.

The choice of treatment for BRBNS depends upon the site and severity of the lesion. Treatment for symptomatic gastrointestinal lesions consists of conservative management and surgical resection. When there is only occult blood loss, oral iron supplementation, blood transfusions, and pharmacological methods should be the first choice. Notably, Sirolimus (rapamycin) is a novel antiangiogenic agent, which acts by inhibiting the mTOR pathway to reduce the size of venous malformation lesions and controls gastrointestinal bleeding [5-7]. Endoscopic approaches and surgical resection are recommended for serious chronic bleeding. Taken together, we decided to select conservative approaches for this patient; the rise of hemoglobin indicated the effectiveness of intravenous iron supplementation.

\section{Conclusion}

We report a case of BRBNS involving growth retardation and pubertal delay resulting from IDA. For patients with recurrent melena and anemia accompanied by cutaneous vascular malformations, BRBNS should be suspected, and endoscopic evaluation is essential to explore the whole gastrointestinal tract. Moreover, IDA is a common symptom of BRBNS, and thus the nonhematologic effects should not be ignored. We suggest that BRBNS should be included in the differential diagnosis of pubertal delay.

\section{Statement of Ethics}

The authors have no ethical conflicts to disclose.

\section{Disclosure Statement}

The authors have no conflicts of interest to declare.

\section{References}

1 Soblet J, Kangas J, Nätynki M, Mendola A, Helaers R, Uebelhoer M, et al. Blue Rubber Bleb Nevus (BRBN) Syndrome is caused by somatic TEK (TIE2) mutations. J Invest Dermatol. 2017 Jan;137(1):207-16.

2 Singal A, Vohra S, Sharma R, Bhatt S. Blue Rubber Bleb Nevus Syndrome with musculoskeletal involvement and pulmonary stenosis. Indian Pediatr. 2016 Jun;53(6):525-7.
3 Ghosh K. Non haematological effects of iron deficiency - a perspective. Indian J Med Sci. 2006 Jan;60(1):30-7.

4 Soliman AT, De Sanctis V, Yassin M, Adel A. Growth and Growth hormone - Insulin like growth factor -I (GH-IGF-I) axis in chronic anemias. Acta Biomed. 2017 Apr;88(1):10111.

5 Yuksekkaya $\mathrm{H}$, Ozbek O, Keser M, Toy H. Blue rubber bleb nevus syndrome: successful treatment with sirolimus. Pediatrics. 2012 Apr;129(4):e1080-4.
6 Cardoso H, Dias JA, Silva M, Vilas-Boas F, Trindade E, Tavares M, et al. 'Education and Imaging. Gastrointestinal: successful treatment with sirolimus of a patient with blue rubber bleb nevus syndrome. J Gastroenterol Hepatol. 2016 Mar;31(3):519.

7 Wang KL, Ma SF, Pang LY, Zhang MN, Hu LY, Liu MJ, et al. Sirolimus alternative to blood transfusion as a life saver in blue rubber bleb nevus syndrome: A case report. Medicine (Baltimore). 2018 Feb;97(8):e9453. 